\title{
THE DESIGN OF TERRESTRIAL TRUNKED RADIO (TETRA) COMMUNICATION SYSTEM AT JUANDA AIRPORT
}

\author{
Devi Miasari, Ari Wijayanti, OkkiePuspitorini \\ PoliteknikElektronikaNegeri Surabaya \\ Kampus PENS KeputihSukolilo Surabaya 60111, Tel +62315947280 \\ E-mail: ariw@eepis-its.edu, okkie@eepis-its.edu
}

\begin{abstract}
Nowdays the application of wireless communication system at the airport area is very important as it is used to support the services and savety of people. In the beginning the communication is done by using Handy Talkie (HT) and the communication is limited on voice. To increase the working operation and savety of public the data communication, besides the voice, is needed. This research is designed to use wireless communication using TETRA technology on frequency $450 \mathrm{MHz}$ by counting the linkbudget and are coverage of the airport. The calculation shows that the more the distance between $\mathrm{Tx}$ and $\mathrm{Rx}$, the bigger the pathloss will be. When the distance is $5 \mathrm{~km}$, the pathloss reaches $144,46 \mathrm{dBm}$ on the antenna receiver $1,25 \mathrm{~m}$. Menwhile the Rx heigh antenna does not have any significance effect on the pathloss. The coverage area for the plan can reach the distance $3,3 \mathrm{~km}$ when the power of transmission is $33 \mathrm{dBm}$ which is enough to cover the whole area of the airport.
\end{abstract}

Keywords: TETRA, Link Budget, Pathloss, Airport

\section{INTRODUCTION}

Nowdays, the application of wireless communication system at the airport area is very important as it is used to give qualified services and savety of public. In the beginning the operation of communication between workers is done by using Handy Talkie (HT). HT is a device of analog communication that is limited onlu on voice rather than data. This communication does not support quick and safe operation. Therefore, to increase the efficiency of working and safe transportation, better communication system is needed. The communication should be able to send not only the voice but also the data. The data communiation is able to ease the process of uploading /down loading from the control room to all area in the airport, besides the data transmission can be used to transmit the video for the security of location. 
One of communication technologies that has already been applied is Terrestrial Trunk Radio(TETRA).TETRA is a digital wireless communication system that has been approved by European Telecommunications Standards Institute (ETSI)which was accepted as official digital standard for Profesional Mobile Radio (PMR) [1] in Europe. The digital communication provides better privacy, qualified audio, fast data transmission and telephone network, like internet. The use of radio communication uses the standart TETRA, which is intended for professionals who wants to use better solid communication that is charged cheaper than GSM system [1]. Therefore, this paper just presents the design of TETRA communication in Juanda Airport via link budget calculation and area coverage.

This paper is begun with an introduction in part 1. Part 2 shows some previous studiesand part 3 is about Originality. Part 4 is the design system. Part 5 contains the experiment and analysis and ends with a conclusion.

\section{RELATED WORKS}

Many researchers have discussed the use of TETRA technology using vireless communication in airports [2][3][4]. Faihan D. Alotaibiet all have studied about "TETRA Outdoor Large-Scale Received Signal Prediction Model in Riyadh Urban Area". In this research, a log-distance model is used to predict the signal power on the open area. The system uses TETRA on frequency operation at 300-400 Mhz in Riyadh city [2]. GianmarcoBaldini made investigation on the use of wireless communication technology and the sinergy potency between public safety and the existing comercial network. This research gives a conclusion that the design of system needs to use some technologies and the existing spectrums [3]. Augusto et all made a research about the use of wireless technology at Portugal airport. He used the existing network, TETRA and CDMA. The research stated that the technology was very solid to be used in the Portugal airport [4]. In this research, the application of TETRA is implemented at the area of Juanda Airport.

\section{ORIGINALITY}

Many researchers have applied the TETRA wireless technology in the world [2]-[4]. But so far, the technology has not been implemented for communication in airports in Indonesia which have different geography and environmental condition. Therefore, this research is designed to use the TETRA technology at Juanda Airport Surabaya in order to find out the coverage area and link budget calculation that is appropriate to real site condition. This research is unique because the data are taken from secondary sources in the specific environment at the airport.

\section{SYSTEM DESIGN}

The design of TETRA technology for communication at Juanda airport is shown in Fig. 1. The plan is begun with TETRA parameter and the collection of secondary data such as the specification of instrument, location 
data and airport environment of Juanda Airport. The main important parameter in the TETRA technology is shown in Table 1 [2]. The data analysis is done by calculating the link budget and predicting the area coverage. And the result of the analysis is shown in a website and an area coverage map.

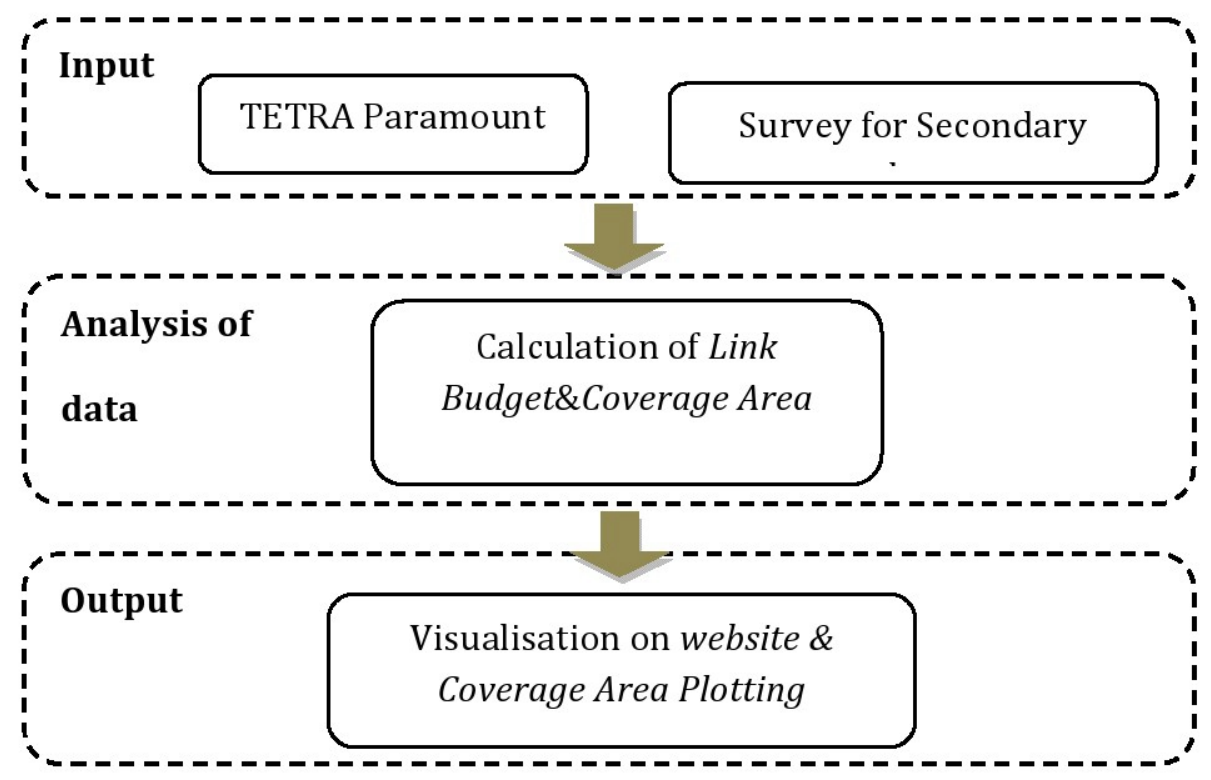

Figure 1. Block Diagram of System Design

Table 1. Main Parameter on TETRA [2]

\begin{tabular}{|l|l|l|}
\hline No. & System Parameter & ParameterValue / Explanation \\
\hline 1 & Frequency Up Link (MHz) & $450-460$ \\
\hline 2 & Frequency Down Link (MHz) & $460-470$ \\
\hline 3 & Digital Modulation & $\pi / 4 \mathrm{DQPSK}, 2$ bit per symbol \\
\hline 4 & Carrier Bandwidth & $\begin{array}{l}25 \mathrm{KHz}, \quad 25 / 4=6.25 \mathrm{MHz} \text { per } \\
\text { canal) }\end{array}$ \\
\hline \multicolumn{2}{|c|}{ TransmitterParameter Tx } \\
\hline 5 & Minimum Power Transmitter & $2 \mathrm{~W}(+33 \mathrm{dBm})$ \\
\hline 6 & Maximum Power Transmitter & $40 \mathrm{~W}(+46 \mathrm{dBm})$ \\
\hline 7 & Height of Transmitter & $10 \mathrm{~meter}$ \\
\hline 8 & Gain Tx & $7 \mathrm{dBi}$ \\
\hline 9 & Cable Loss & $1 \mathrm{~dB}$ \\
\hline \multicolumn{3}{|c|}{ Receiver Parameter Rx } \\
\hline 9 & Gain Rx & $3 \mathrm{~dB}$ \\
\hline 10 & Noise Figure & $5 \mathrm{~dB}$ \\
\hline
\end{tabular}

\section{EXPERIMENTAL AND DATA ANALYSIS}

Based on TETRA parameter and secondary survey data, calculation is done to find out the link budget and area coverage of the airport. 


\subsection{Link Budget}

Link Budget is calculation of attenuation and enforcement used as early calculation in the plan of a communication system within a certain area. The main important element in the link budget is pathloss, EIRP, Receive Signal Level, SNR, SOM and dynamic path of the way.

\section{A. Pathloss.}

Pathloss is an important component in calculation and analysis design about the Link Budget of communication system. The Pathloss is based on a model of Okumura-Hatta on Sub Urban area and the pathloss is obtained on the basis of equation (1) [5].

$$
\begin{aligned}
& \mathrm{L}(\mathrm{dB})=69,55+26,16 \log _{10} f_{M h z}-13,82 \log _{10} h_{\mathrm{b}}-\mathrm{A}\left(h_{\mathrm{m}}\right)+\left(44,9-6,55 \log _{10} h_{\mathrm{b}}\right) \\
& \log _{10} \mathrm{R}-2\left(\log 10\left(f_{M h z} / 28\right)\right) 2+5,4
\end{aligned}
$$

where $\mathrm{R}$ is the distance between $\mathrm{Tx}$ and $\mathrm{Rx}$, whereas $\mathrm{F}_{\mathrm{Mhz}}$ is a frequency carrier, $\mathrm{Hm}$ the height mobile station $(\mathrm{m})$, and $\mathrm{Hb}$ the height of Base station (m). The result of pathloss calculation is shown in Figure 2.

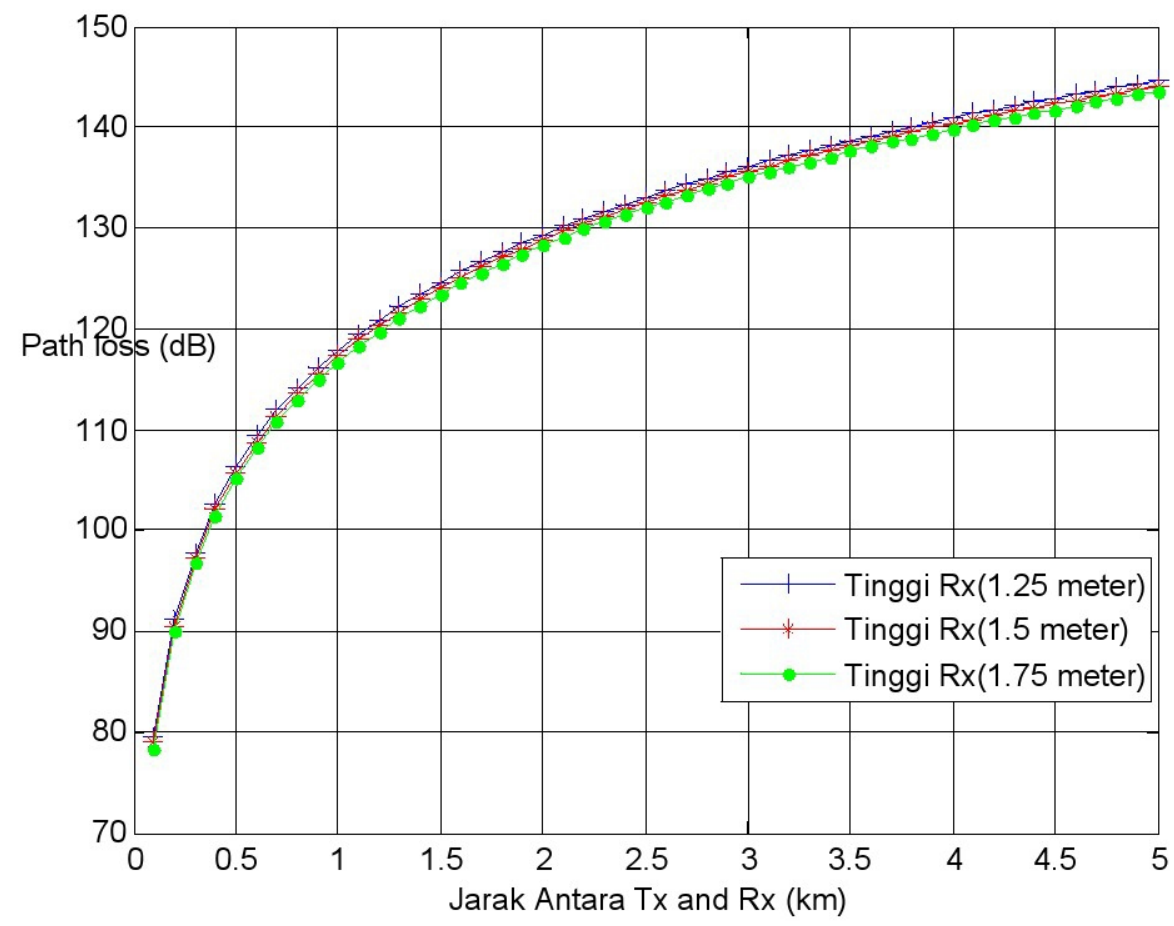

Figure 2.Pathloss graph on various distance receiver $(\mathrm{Rx})$

The figure 2 shows that when the distance between $\mathrm{Tx}-\mathrm{Rx}$ is getting far, the pathloss is also getting bigger. This is due to the attenuation that is influenced by the bigger environment. Meanwhile the height of receiver antenna does not give significance change to the pathloss. When the distance 
is $5 \mathrm{~km}$ with antenna height 1.25 meter, the pathloss is $144.46 \mathrm{~dB}$. When the antenna is 1,5 meter the pathlossequals $143.91 \mathrm{~dB}$, and when the height is 1.75 meter, the pathloss reaches $143.36 \mathrm{~dB}$.

\section{B. Effective Isotropic Radiated Power (EIRP)}

EIRP or Equivalent Isotropic Radiated Power is a power value transmitted by directional antenna to create the top power that is examined on maximum radiated directional antenna, and Definition EIRP can be presented 2 [5]:

EIRP $(\mathrm{dBm})=$ Tx power + Gain antenna - cable loss

whereTx Power $(\mathrm{dBm})=$ transmitted power $(\mathrm{dBm})$

Table 2.Influence of transmition Power to EIRP

\begin{tabular}{|c|c|}
\hline Transmission Power Value (dBm) & EIRP Value (dBm) \\
\hline 33 & 50.0119 \\
\hline 46 & 37.0119 \\
\hline
\end{tabular}

The results of EIRP with transmission power $+33 \mathrm{dBm}$ and $46 \mathrm{dBm}$ are shown on Table 2

\section{Receive Signal Level (RSL)}

RSL is a signal level that is accepted on the receiver and its value is bigger than sensitivity of the receiver (RSL $\geq$ Rth). The receiver sensitivity refers to the device's sensitivity on receiver. RSL is gained on the basis of equation 3 [5]:

RSL $=$ EIRP - Path Loss + GRX - LRX

whereGrx refers to receiver's gain $(\mathrm{dB})$ and Lrx is the loss of receiver cable $(\mathrm{dB})$

Figure 3 shows RSL graph on EIRP Pt $=-43 \mathrm{dBm}$ and Pt $=-33 \mathrm{dBm}$. The figure also shows that the power values received depend on transmission power and loss condition around it. 


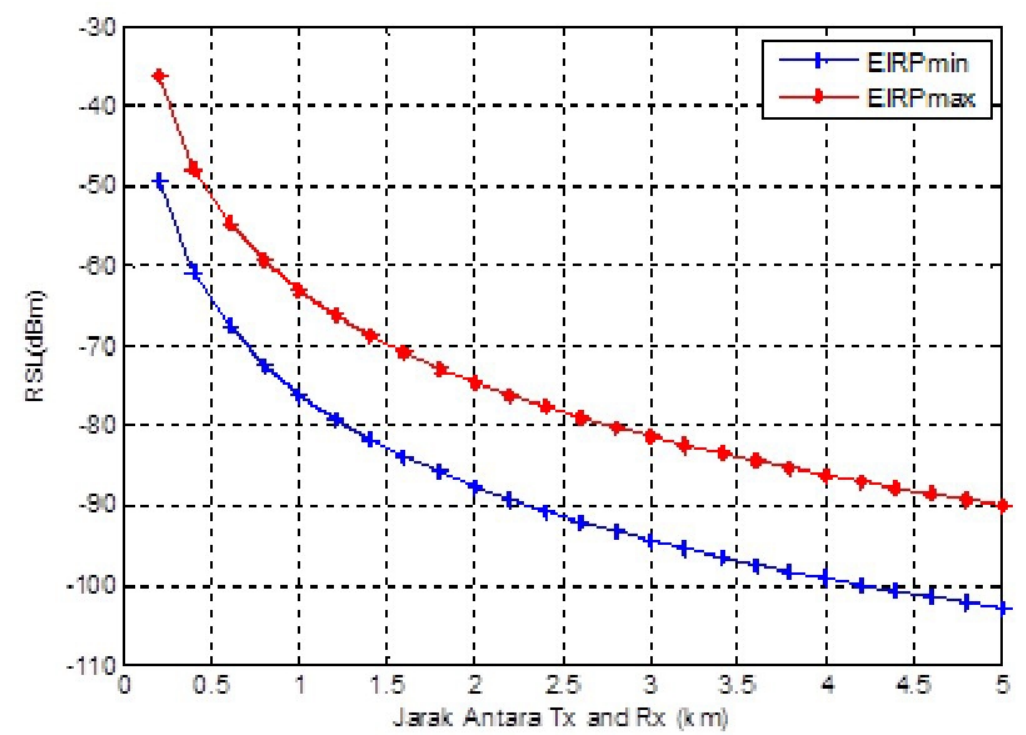

Figure 3. RSL Graph versus Distances on EIRP condition

\section{Signal to Noise Ratio (SNR)}

SNR or signal to noise ratio refers the signal quality on the system of measurement. SNR can be calculated by using the equation 4 [5].

$$
\begin{aligned}
& \operatorname{SNR}(d B)=P s(d B m)-N(d B m) \\
& P s(d B m)=P t+G t+G r-P L(d) \\
& N(d B m)=-174+10 \log 10 B+F
\end{aligned}
$$

wherePt is the power received $(\mathrm{dBm})$, Gt is Gain of transmitter $(\mathrm{dB}), \mathrm{Gr}$ is the received gain $(\mathrm{dB}), \mathrm{PL}$ is Pathloss on distance $(\mathrm{dB}), \mathrm{B}$ is Bandwidth $(\mathrm{Hz})$ and $\mathrm{F}$ refers to Noise Figure (dB). 


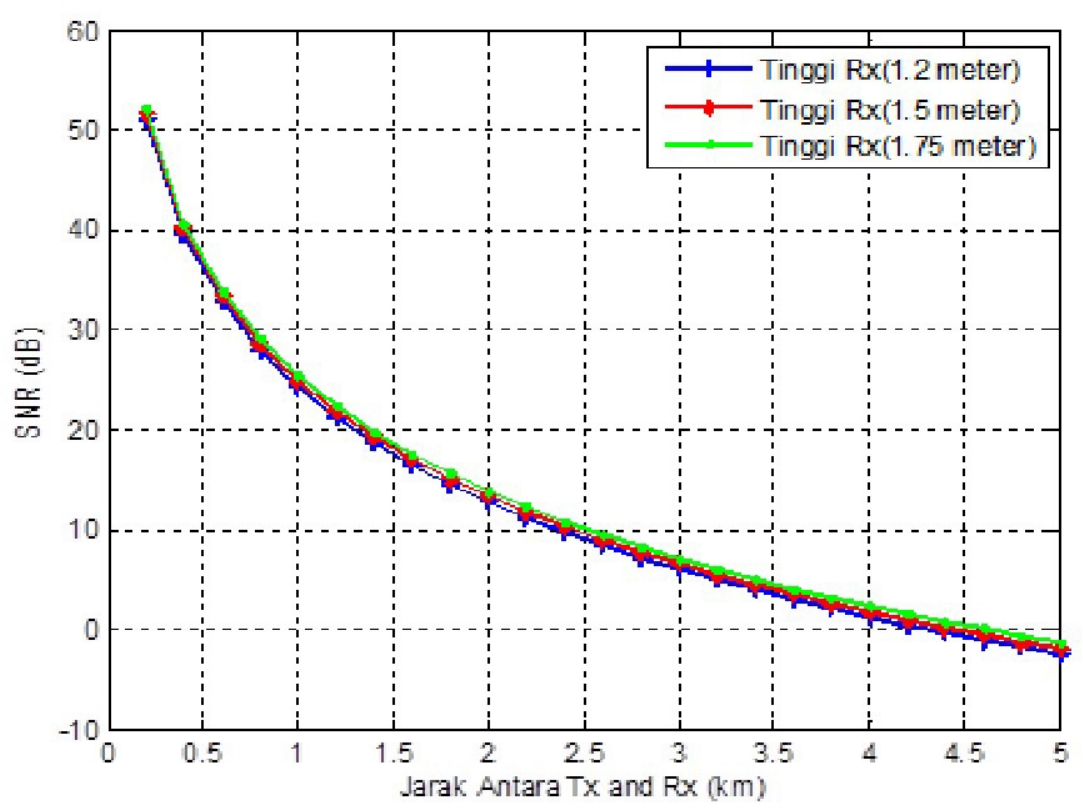

Figure 4. SNR Graph for distance function

Figure 4 shows SNR graph against the distance function. When the distance between $\mathrm{Tx}-\mathrm{Rx}$ gets further, the SNR values are getting smaller due to the big loss. When the distance is $0.5 \mathrm{~km}$ SNR value is $51.14 \mathrm{~dB}$, but when the distance $5 \mathrm{~km}$, the value is $-1.36 \mathrm{~dB}$.

\section{E. Coverage Area}

On the calculation of coverage area, dynamic attenuationmethodis considered as the main reference for minimum power level accepted on certain distance on power average level from an urban area. The dynamic attenuation method is obtained from equation 8[5]:

$\mathrm{P}_{\mathrm{r}}=\mathrm{P}_{\mathrm{t}}-\mathrm{L}$

Where $\mathrm{P}_{\mathrm{r}}$ is power received, Pt refers to transmission power and $\mathrm{L}$ is the pathloss. To execute the coverage area, the calculation of dynamic attenuation needs to be done. The results of dynamic attenuation calculation is shown on Figure 5. 


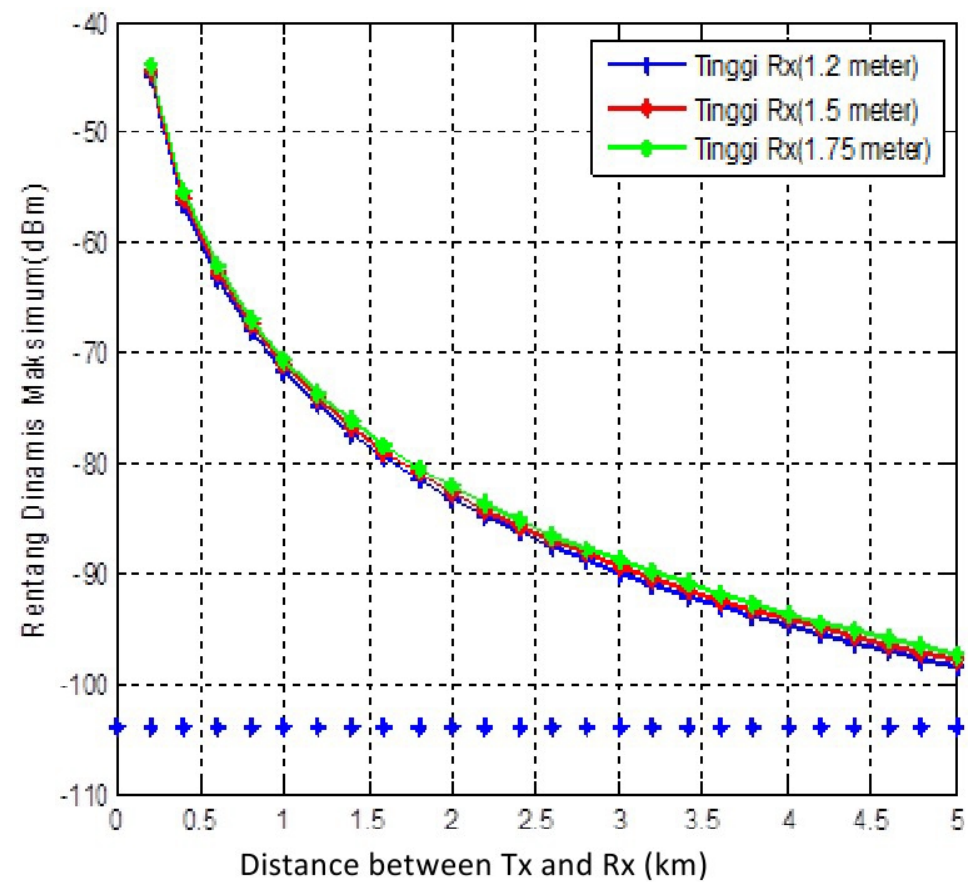

(a)

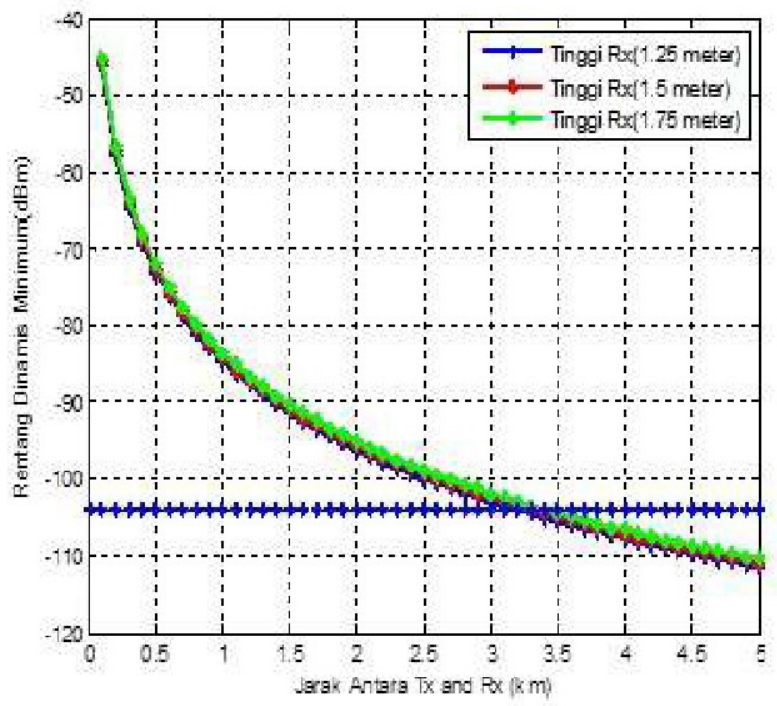

(b)

Figure 5. Results of coverage area calculation (a) $\mathrm{Pt}=43 \mathrm{dBm}$ (b) $\mathrm{Pt}=33 \mathrm{dBm}$

Figure 5 shov. Distance between $\mathrm{Tx}$ and $\mathrm{Rx}(\mathrm{km})$ .sr maximum signal distances can be received on the fact that the threshold from big equipment - $104 \mathrm{dBm}$. When the power transmitter is $33 \mathrm{dBm}$ the coverage area reaches only $3.3 \mathrm{~km}$. When the power is increased up to $43 \mathrm{dBm}$, the coverage area distance may reach $5 \mathrm{~km}$. 
The result of TETRA design is performed in a table and the coverage area is in Figure 8. The link budget table makes designers of communication easy to design and apply the TETRA technology in Juanda Airport area.

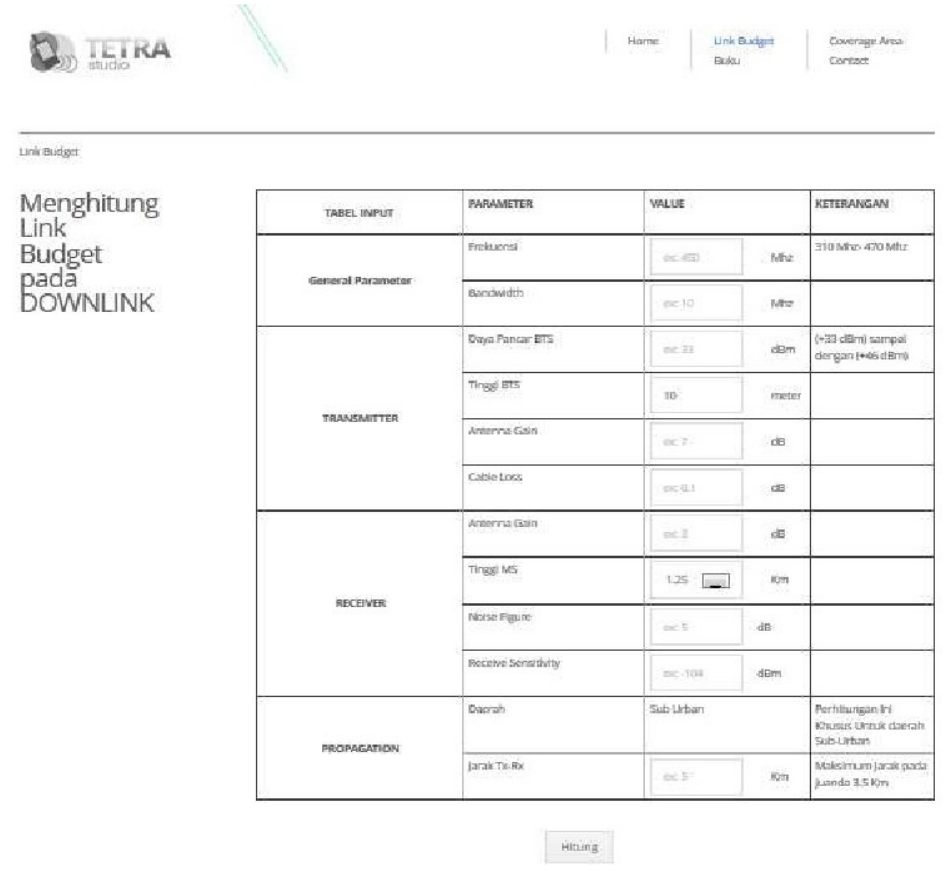

(a)
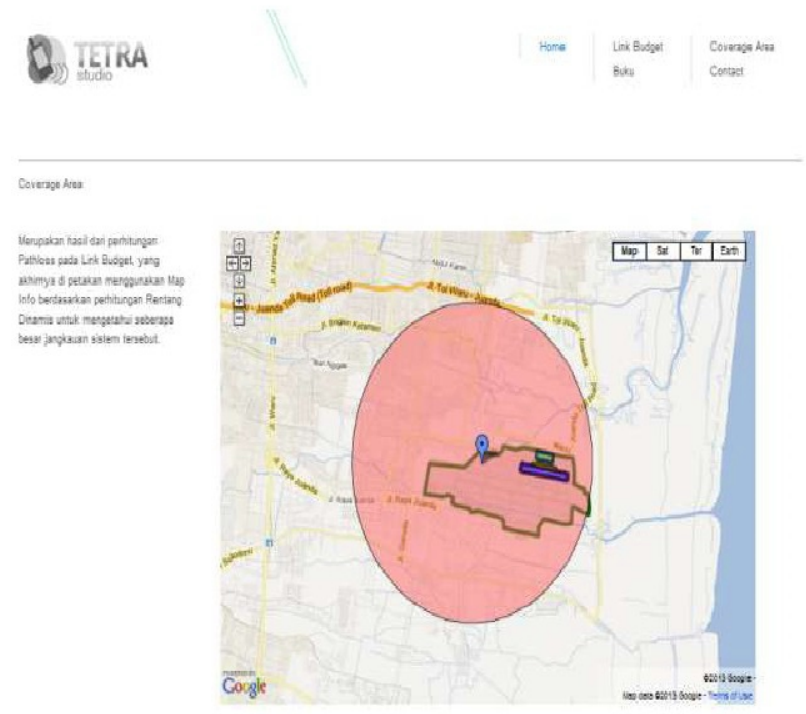

(b)

Figure 6 (a) The performance of link budget calculation on website, and (b)The performance of coverage area and position Tx on website.

\section{CONCLUSION}


The design of TETRA technology for wireless communication is influenced mostly by the environment condition. In the area of Juanda Airport, the communication has pathloss which is getting bigger when the distance of $\mathrm{Tx}-\mathrm{Rx}$ is getting far. When the distance is $5 \mathrm{~km}$ and antenna height is $1.25 \mathrm{~m}$, the pathloss is $144.46 \mathrm{dBm}$. The height of antenna does not influence the value of pathloss. The plan design for the coverage area in the airport is reached when the distance is $3.3 \mathrm{~km}$ and transmission power is +33 $\mathrm{dBm}$. This distance, $3.3 \mathrm{~km}$, is fairly enough for making good communication in all area in the airport.

\section{Acknowledgements}

Great appreciation is directed to PT AngkasaPura at Juanda Airport who has given assistance to finish the research.

\section{REFERENCES}

[1] ETSI TR .Technical Report Terrestrial Trunked Radio (TETRA); Release 2;Designer's Guide; TETRA High-Speed Data (HSD); TETRA Enhanced Data Service (TEDS), V1.1.1 (2007-10).

[2] Faihan D. Alotaibi and Adel A. Ali, TETRA Outdoor Large- Scale Received Signal Prediction Model Based on recent RF Measurements in Riyadh Urban Area, proceeding IEEE Wireless and Microwave Technology, Clearwater, Florida, USA,2006.

[3] Gianmarco Baldini , Ramon Ferrus, Oriol Sallent, Paul Hirst, Serge Delmas, Rafał Pisz, The evolution of Public Safety Communications in Europe: the results from the FP7 HELP project,ETSI Reconfigurable Radio System Workshop, Sophia Antipolis, France,2012.

[4] Augusto Casaca, Tiago Silva, António Grilo, Mário Nunes, Franck resutto, Isabel Rebelo, The Use of Wireless Networks for the Surveillance and Control of Vehicles in an Airport Environment, Proceedings of the 11th IFIP TC6 International conference on Personal WirelesComunications, 2006.

[5] Spectrum Planning Team,Investigation of Modified Hata Propagation Models,Australian communications Authority, April 2001.

[6] ETSI, Terrestrial Trunked Radio (TETRA), voice plus data (V+D), designer's guide, part1",ETR 300-1, May 1997.

[7] Dr.-Ing.Martin Steppler, Dr.-Ing. Peter Sievering, Stephan Kerkhoff, Tony Gray.,Evolution of TETRA To a 4G All-IP Broadband Mission Critical Voice Plus Data Professional Mobile Radio Technology,Germany, 22 november 2011. 